\title{
A Message from the President: EMS and COVID-19
}

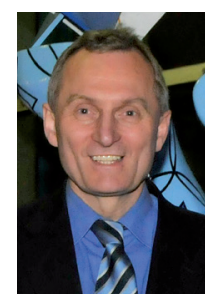

Dear EMS members,

In these unusual times of the COVID-19 crisis with so many tragic losses all over the world and, in particular, also all over Europe, with health systems coming to their limits, with lockdowns of whole countries, with the closing of schools and universities, with pure online-teaching, and many personal tragedies and inconveniences, also the EMS is challenged.

First of all the European Congress of Mathematics $8 \mathrm{ECM}$ in Portorož, Slovenia had to be postponed and is now planned for June 20-26, 2021 (see https://www.8ecm. $\mathrm{si} /$ ). In view of this decision we have already announced the 2020 prize winners (https://www.8ecm.si/news/69).

Furthermore, the planned EMS council cannot take place in Bled in July but will be carried out in an online format on Saturday, July 4, 2020 to decide about future vice presidents, executive committee members, the budget for the years 2020/21 and the place of the next congress in 2024 (here Sevilla and Lisbon are the candidates).

If possible, we plan a restart of the non-virtual EMS activities and have an in-person council meeting in Edinburgh on October 30,2020, where we will discuss the plans for the future of EMS that include the formation of activity groups, the organization of specialized meetings, and the start of a young academy. This meeting will be combined with the executive and presidents meetings that had to be cancelled in March.
We are also planning a celebration of the 30th anniversary of the EMS with a one-day meeting in Edinburgh on October 29,2020. More details about these events will be announced in due time.

As we all know, a crisis always also offers a chance for positive developments. As we have noticed in the crisis, mathematics is entering every-day life much more than usual, with growth models, statistical analysis, infection prognostics, etc. Mathematical models are used for political decision making more than ever, but very little is reported about uncertainty in the data and the models. This development is a chance for mathematics but also bears the risk that we later go back to the times where scientific results are questioned because of this uncertainty. To my opinion it is the duty of the mathematical community to increase research in this direction and also to inform the public about the results. The EMS has already started initiatives in this direction, the Applied Mathematics Committee is forming a special research group on COVID-19 related mathematical research and the Committee for Raising Public Awareness is informing the public about the mathematics behind the pandemic crisis. But much more is needed and I appeal to the mathematical community to get more active in this respect.

With this appeal I wish you all the best, in particular good health, and hope to meet many of you soon again in person. 